Connotas. Revista de crítica y teoría literarias 
PQ6001

.C65

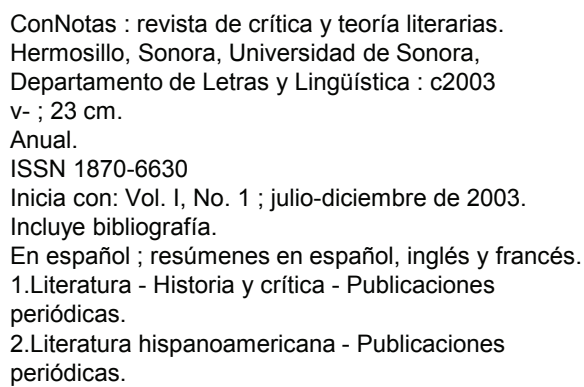

Área de Análisis Bibliográfico, Dirección de Servicios Universitarios, Universidad de Sonora

CONNOTAS. REVISTA DE CRÍTICA Y TEORÍA LITERARIAS. Enero 2014 - diciembre 2015, es una publicación anual editada por la Universidad de Sonora, a través de la División de Humanidades y Bellas Artes, en el Departamento de Letras y Lingüística. Blvd. Luis Encinas y Blvd. Rosales s/n, Col. Centro, C.P. 83000, Hermosillo Sonora; Tel. (662) 2592 136, (662) 2592 157, <www.uson.mx>, <http://www.connotas.uson.mx, connotas@capomo.uson.mx>. Editor responsable: Rosario Fortino Corral Rodríguez. Reservas de Derechos al Uso Exclusivo núm. 04-2015-060316081500-102. ISSN: 1870-6630; ambos otorgados por el Instituto Nacional del Derecho de Autor. Licitud de Título núm. 13434 y de Contenido núm. 11007, otorgados por la Comisión Calificadora de Publicaciones y Revistas Ilustradas de la Secretaría de Gobernación. Este libro se publicó con el apoyo del Programa Integral de Fortalecimiento Institucional OP/PROFOCIE-2014-26MSU0015Z-13-01

Se autoriza la reproducción total o parcial de los contenidos de la presente publicación, siempre y cuando se acredite adecuadamente el origen de los mismos.

Datos de contacto para la publicación: División de Humanidades y Bellas Artes, Departamento de Letras y Lingüística; Apartado Postal 793, Col. Centro, C.P. 83000, Hermosillo, Sonora, México. Tels.: (662) 259-21-87, Tel-fax 212-55-29. Correo electrónico: connotas@,capomo.uson.mx Página web: http://www.connotas.uson.mx 


\section{Connotas. Revista de crítica y teoría literarias}

Núm. 14-15, años 2014-2015

COORDINADOR DE ESTE NÚMERO

Manuel Llanes García

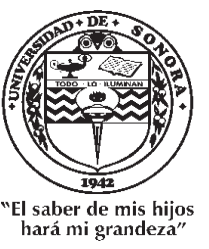

UNIVERSIDAD DE SONORA 
Universidad DE SONORA

RECTOR

Heriberto Grijalva Monteverde

VICERRECTORA

Arminda Guadalupe García de León Peñúñuri

Secretario General Académico

Enrique Fernando Velázquez Contreras

División de Humanidades y Bellas Artes

Fortino Corral Rodríguez

Departamento de Letras y Lingǘ́stica

Ana Bertha de la Vara Estrada

\begin{tabular}{|c|c|}
\hline \multicolumn{2}{|c|}{ Comité Editorial Interno } \\
\hline $\begin{array}{r}\text { Cé } \\
\text { Rosa M } \\
\text { Fortin } \\
\text { Leticia } \\
\text { Jesús A } \\
\text { Gab } \\
\text { María Ri }\end{array}$ & $\begin{array}{l}\text { Icedo } \\
\text { la Encinas } \\
\text { Rodríguez } \\
\text { Figueroa } \\
\text { rro Gálvez } \\
\text { Osuna } \\
\text { te Martínez }\end{array}$ \\
\hline \multicolumn{2}{|c|}{ DIRECTOR } \\
\hline \multicolumn{2}{|c|}{ CONSEJO INTERNACIONAL } \\
\hline Giuseppe Bellini & Carlos Pacheco † \\
\hline Universidad de Milán & Universidad Simón Bolivar \\
\hline Luis Beltrán Almería & Rafael Olea Franco \\
\hline Universidad de Zaragoza & El Colegio de México \\
\hline Helena Beristáin $†$ & Joan Oleza Simó \\
\hline Universidad Nacional Autónoma de Méxic & Universidad de Valencia \\
\hline Raúl Bueno-Chávez & Julio Ortega \\
\hline Dartmouth College & Brown University \\
\hline Evodio Escalante & Luz Aurora Pimentel \\
\hline Universidad Autónoma Metropolitana & Universidad Nacional Autónoma de México \\
\hline Beatriz González-Stephan & Susana Reisz \\
\hline Rice University & The City University of New York \\
\hline Aníbal González & José Carlos Rovira \\
\hline Yale University & Universidad de Alicante \\
\hline Aurelio González Pérez & Charles Tatum \\
\hline El Colegio de México & The University of Arizona \\
\hline Yvette Jiménez de Báez & Jorge Urrutia \\
\hline El Colegio de México & Universidad Carlos III de Madrid \\
\hline Nelson Osorio Tejeda & Emil Volek \\
\hline Universidad de Santiago de Chile & Arizona State University \\
\hline
\end{tabular}




\section{Índice}

\section{Artículos}

Marcos de Obregón en la novela picaresca

Gonzalo Aguayo Cisternas …………………………………………. 9

El quehacer historiográfico de los fantasmas. Aproximaciones a Doña Inés contra el olvido de Ana Teresa Torres

María Carrillo

Dance la luz ocultando su rostro. Resonancias lezamianas de la danza

Alfonso René Gutiérrez

Participación de la mujer en la edición de una revista literaria en los años sesenta del siglo XX en México: El Rebilete

Arturo Texcahua Condado

Espacio, lenguaje e identidad en Estrella de la calle sexta de Luis Humberto Crosthwaite

José Miguel Candelario Martínez

Influencias platónicas en la cuentística arreolina

Iram Isaí Evangelista Ávila, Erbey Mendoza Negrete

La construcción del lector en la narrativa policial de Borges.

Teoría y práctica de ¿uu género menor?

Alejandra G. Amatto Cuña

Proyectos de restitución mitológica: la antología Paisajes

del limbo y la colección Singulares

Javier Hernández Quezada 
Madre de las Historias. Idea de religión en un cuento

de Alberto Chimal

Manuel Llanes García

Un epílogo de La ventana indiscreta. Una poética materialista del cine

Pablo Huerga Melcón

Notas

Juan Carlos Onetti: territorios de la aventura

Rocío Antúnez Olivera

\section{Reseñas}

Jon Juaristi. Miguel de Unamuno.

Emmanuel Martínez Alcocer

Iván Vélez. Sobre la Leyenda Negra.

José Manuel Rodríguez Pardo

Dominique Maingueneau. Manuel de linguistique pour les textes

litteraires

Gerardo López Cruz

Abstracts

Résumés 267

Normas editoriales 277 
Connotas. ReVISTA DE CRíticA Y TEORía literaRias/Núm. 14-15/2014-2015

\title{
Marcos de Obregón en la novela picaresca
}

\author{
Gonzalo Aguayo Cisternas*
}

Resumen:

La novela barroca Marcos de Obregón de Vicente Espinel tiene vínculos innegables con la picaresca. Sin embargo, en estricto rigor, no se trata de una narración de género puro, pues los rasgos que definen una obra de esta corriente tienen directa relación con las cualidades del protagonista. En este caso, la historia con carácter de etopeya de un escudero que relata su vida desde su vejez remite directamente a la figura del autor, hecho trascendente que condiciona toda la axiología de la obra. De esta forma, la narración autobiográfica, la estructura, los episodios truhanescos y los personajes marginales que actúan como pícaros genuinos son los elementos que conectan esta novela con el género; pero esta, sin embargo, representa connotaciones semánticas distintas a las que mueven a los relatos canónicos de aquella manifestación literaria.

Palabras clave:

Literatura, género, Siglo de Oro, Vicente Espinel, Marcos de Obregón, picaresca, pícaro, arquetipo, autobiografía.

Los vínculos de las Relaciones de la vida del escudero Marcos de Obregón y el género picaresco ofrecen diversidad de perspectivas. Así se advierte en el diálogo académico que se ha sostenido de forma

* Universidad de Concepción. 
permanente a partir del intento por establecer en qué medida la "novela"1 de Espinel cabe dentro de los cánones de esta corriente literaria, que tuvo su auge en el Siglo de Oro hispánico. No obstante, en líneas generales, la mayoría de las investigaciones coinciden en señalar que el texto de Espinel es una continuación del camino trazado por este tipo de narraciones, aunque las opiniones disienten respecto de su cercanía o lejanía en relación a los principios genéricos que las rigen.

El primer síntoma del problema lo constituye el personaje protagonista. Gran parte de los estudios como los de Rico, Bataillon, Lázaro Carreter, Navarro González, Carasco Urgoiti, Lara Garrido, Rallo Gruss, entre otros, advierten que el escudero Marcos de Obregón, dadas sus singulares características psicosociales y éticas, no entra en los cánones del arquetipo del pícaro. Sin embargo, las antologías sobre novela picaresca, por lo general, incluyen en sus

\footnotetext{
${ }^{1}$ El empleo de esta denominación, realizada con una mirada actual, que agrupa a las obras en prosa, reemplaza al de Relaciones que utiliza Espinel, puesto que en la época en que la obra salió a la luz pública, en 1618, la novela, tal y como la conocemos hoy en día, estaba en pleno proceso de gestación. En 1605, Cervantes había publicado la primera parte del Quijote. El texto, que ha sido instaurado como la primera novela moderna, bien es sabido, no utiliza este nombre. Posteriormente, en 1613, el propio Cervantes publicaba una serie de historias cortas que bautiza, de acuerdo al modelo del relato breve italiano, como Novelas ejemplares. Teijeiro observa que la multiplicidad de términos con que las incipientes novelas de aquella época solían denominarse obedece a un proceso de consolidación que dificulta la taxonomía de los relatos en prosa del Barroco hispánico: "Si repasamos el panorama narrativo español del Siglo de Oro, podemos advertir que no existe publicado ningún relato bajo el epígrafe de 'novela'. De esta manera, se habla de 'crónica', 'tratado', 'vida', 'historia', 'trabajos'..., etc., que indican la disparidad terminológica en la que se apoyan los escritores" (66). Respecto a aquellos textos que responden a la denominación de "vida", un ejemplo lejano, que pudo influir en esta novela, lo representa la Vida de Esopo, o los más inmediatamente cercanas al escrito de Espinel como la Vida de Lázaro de Tormes $y$ de sus fortunas y adversidades o la Vida del Buscón don Pablos, obras cuyo tronco en común lo representa la historia autobiográfica de un personaje, lo que da luces acerca de la naturaleza que irá adquiriendo ese tipo de relatos como referentes para el género de la picaresca.
} 
volúmenes el relato de Espinel. Esta dicotomía hace visible la contradicción que afecta la obra, en cuyo seno se albergan, también, otros géneros narrativos.

Pero, previo a ello, subyace el dilema de fondo de la cuestión picaresca acerca de la definición y el origen del personaje. Las dificultades que conlleva la búsqueda de evidencias que indiquen las conexiones del Marcos de Obregón con el género se relacionan, en primer término, con la multiplicidad de perspectivas que existe sobre esta genuina manifestación literaria, cuyas fronteras y características no están bien señaladas (Navarro González 79). Rey, incluso, opina que el calificativo que se le aplique a esta obra en prosa dependerá del concepto que cada cual tenga de la novela picaresca (680). No obstante, si observamos el fenómeno de la novela barroca y el mecanismo creativo que la catapultó, es posible advertir que los escritores, más que ceñirse estrictamente a un género determinado, cuya taxonomía y definición siempre es posterior a la obra, estuvieron atentos al panorama narrativo -y literario, en general- del pasado clásico y reciente del autor, como también al que se desarrollaba en su tiempo. ${ }^{2}$ Ellos supieron digerir sus lecturas para crear otras historias con algunos de sus elementos transformados para sus propios fines estéticos y éticos. Es el procedimiento de la imitatio como fuerza motriz. Así ocurrió, por ejemplo, con La Celestina, el Lazarillo, el Gużmán, el Quijote y el Buscón, que se erigieron como una verdadera

\footnotetext{
${ }^{2}$ Bajtín, que analiza las referencias que históricamente existen entre los diferentes relatos de toda época, denomina a este proceso como reacentuación: "La vida histórica de las obras clásicas es en esencia un proceso continuo de reacentuaciones socio-ideológicas. Gracias a sus posibilidades intencionales, son capaces en cada época de descubrir, en un nuevo trasfondo que las dialogiza, nuevos y nuevos aspectos semánticos" (235). Genette, en tanto, habla de la hipertextualidad, ya que, según él, "no hay obra literaria que, en algún grado y según las lecturas, no evoque otra, y, en este sentido, todas las obras son hipertextuales" (19). No extraña, por tanto, que los autores del período áureo hicieran gala de su fina erudición con la referencia explícita a autores y estetas clásicos que permitiesen advertir su bagaje cultural, pero también este conocimiento les nutrió de material literario suficiente para volcarlo en sus escritos.
} 
columna vertebral de la literatura en prosa del Siglo de Oro español. Estos escritos, con casi un siglo de distancia, ofrecen interesantes vasos comunicantes entre sus historias, pues, en ese orden, cada una de ellas va adoptando episodios, acciones y personajes de las precedentes. Espinel, por cierto, sigue ese cauce y modo creativo en el arte narrativo con un ingrediente especial añadido: su historia personal hecha ficción.

Se hace necesario, a partir de las anteriores aseveraciones, revisar algunas de las principales proposiciones sobre la materia picaresca para forjar un criterio explicativo de las anomalías taxonómicas que afectan a la novela de Espinel, así como también algunos de los juicios críticos vertidos sobre la obra del rondeño.

\section{El pícaro y la picaresca}

\subsection{Orígenes del picaro}

El pícaro, figura literaria con un difuso origen en cuanto a su etimología y significado, ha traspasado su nombre a todo un género novelesco. La crítica, con esmero, ha intentado delimitar el término, del mismo modo como lo ha hecho para tratar de identificar el comienzo de su uso dentro de los textos literarios. Del Monte, quien por cierto resalta aquel complejo afán por su etimología debido a la amplitud de usos que había tenido, indica que la palabra pícaro se pronuncia por primera vez en una farsa llamada Custodia del hombre de Bartolomé Palau en 1547, con la forma de picarote (Itinerario 11). Se plantea, también, que tal nombre provenía del término picar, a partir de su aparición en el poema Alabando la vida del picaro, que data del año 1594 (Heiple 220). Dicha teoría, en tanto, es rechazada por Valbuena Prat, quien acerca más la concepción del término a motivos geográficos, derivados del nombre que reciben los habitantes de Picardía, pero sobre todo de los soldados de la guerra de Flandes, que por la mencionada región francesa pululaban y vaga- 
bundeaban en espera de su destino (16). ${ }^{3}$ Rico, de todas formas, hace hincapié en que el término expande su uso en el último tercio del siglo XVI (116). Ahora bien, sin duda que la profusión explosiva del vocablo, en el concierto novelístico, se debe al impulso que significó la historia autobiográfica Gurmán de Alfarache de Mateo Alemán. El protagonista de esta obra fue quien resultó ser el verdadero prototipo de tales rasgos asociados al nombre, como también el promotor de su propio apodo.

Pese a ello, la controversia gira en torno a la figura de Lázaro de Tormes, como bien advierte Lázaro Carreter (196), pues muchos le señalan como el primer pícaro de la literatura, aunque el personaje nunca usó ni fue señalado con dicho nombre en la historia. No cabe duda que el Lazarillo fue decisivo en todo el proceso de configuración histórica del personaje novelesco, y fue un eslabón esencial para su desarrollo y consolidación. ${ }^{4}$ La obra mostraba por primera vez a un protagonista de baja condición social que contaba un "caso", y aprovechaba para narrar su historia personal desde su infancia menesterosa hasta su presente como aguador del arcipreste San Salvador, a fin de contextualizar y complementar aquel suceso. La obra se nutre de personajes como el Pármeno de La Celestina o Rampín de La lozana andaluza, ambos mozos de muchos amos

${ }^{3}$ Covarrubias ya les menciona en su Tesoro de la lengua castellana o española. De ellos dice lo que sigue: "Vide supra picaño (que el mismo autor define como andrajoso y despedazado), que se pudo decir de pica, que es el asta porque en la guerra, hincándola en el suelo, los vendían ad hastam, por esclavos. Y aunque los pícaros no lo son en particular de nadie, sonlo de la República, para todos los que los quieren alquilar, ocupándolos en cosas viles" (869).

${ }^{4}$ Tal y como sucedió con Celestina, la historia de este singular personaje, una vez que esta trascendiera y se convirtiera en todo un paradigma, continuó escribiéndose en otras páginas. La segunda parte del Lazarillo de Tormes (1555), atribuida al noble Diego Hurtado de Mendoza, y la Segunda parte de la vida de Lazarillo de Tormes, de Juan de Luna (1620), constituyen la evidencia de aquel intento. Ambos relatos, lejanos en el tiempo, se distanciaron del camino que desembocará en la picaresca. El primero de ellos es, según Navarro Durán, una sátira política que encierra una velada crítica al monarca Carlos V (Pícaros 99); el segundo, una respuesta a esta extraña historia, cuyo protagonista se convierte en atún. 
(Navarro Durán, Guðmán XL). Estos últimos no fueron los protagonistas de los relatos, pero ayudaron a que irrumpiera, con posterioridad, un individuo de baja estofa que relatara su propia autobiografía. Quizás, todos ellos representan una especie de protopicaro. ${ }^{5}$

\subsection{La novela picaresca}

A partir de todas esas historias, que mezclan personajes de baja estirpe, se intenta concebir una definición del género. Esta consigue llegar a ser una idea amplia, que aglutina a todas esas historias personales narradas por esos mismos protagonistas:

La novela picaresca ha sido definida, en términos generales, como un relato de un personaje marginal, que lucha por sobrevivir, y por rasgos formales que como la autobiografía, el carácter antiheroico del personaje principal, la intencionalidad satírica, moralidad a contrario, estructura abierta, relato itinerante con orientación realista (Rodríguez 47).

Talens conceptualiza el género como un conjunto de novelas que "no son más que autobiográficas o confesiones de pecadores escarmentados" (20), aunque sugiere que ni Lázaro ni Pablos cumplen con esta última característica. Sin embargo, el problema persiste, puesto que en la definición no está expuesta la moralidad del personaje principal, que es donde está la verdadera génesis de la esencia del pícaro. Guzmán puede caracterizarse como un truhán, jugador, estafador y "ladrón famosísimo", como el propio autor le califica cuando explica el plan de su relato, que era una "confe-

\footnotetext{
${ }^{5}$ Se destaca la presencia de personajes de baja estofa en entremeses y en el teatro prelopista con la ausencia del pícaro como tal en sus escritos. Así, intenta establecer la génesis del personaje, aunque no tuviese, en aquellas obras, tal nombre. Junto a ello, se podía observar una idea de lo que luego sería el pícaro a través de estos "capigorrones hambrientos, estudiantes bromistas, venteros que dan gato por liebre, habladores irrestañables, hidalgos muertos de hambre o hinchados de vanidad, médicos matasanos, poetas chanflones, damas busconas..." (Rico 114).
} 
sión general" (Navarro Durán, Guz̨mán LXV). Estas tropelías no necesariamente las realiza para subsistir a una condición económica miserable, aunque algunas veces la tiene, pero por culpa de su propio proceder. En cambio, Lázaro sí tiene esa necesidad. Sus únicos delitos consisten en robar un poco de comida y vino a sus tacaños y muy poco piadosos y caritativos amos: un ciego tramposo, miembros del Clero o un hidalgo escudero decadente, que aparentaba una falsa realidad económico-social. La genética del Guzmanillo es distinta, pues hereda su infamia de la sangre de sus padres, quienes fueron connotados representantes de sus oficios viles. Ello explica su ruindad, incluso cuando estaba en situación de acomodo con un trabajo honrado y digno. A pesar de esto, su conducta continúa por la mala senda, como si fuese un destino imposible de reorientar, salvo en el arrepentimiento del presente narrativo, cuando ya es un galeote condenado.

Bien explica Rico que hay que distinguir entre el pícaro histórico-social y el personaje literario (117), puesto que el segundo de ellos está construido con un afán y propósito distinto: es, básicamente, una creación que encubre los deseos ocultos de sus autores pertenecientes a otra clase social, no a la de su ficción (Bataillon 211). Dicha voz le permitía al autor tener la libertad de criticar los vicios humanos, de moralizar, a través de la sátira o el humor. Quevedo, en el Buscón, es capaz de sustraer una moraleja en la historia de un pícaro que no cambia sus malas prácticas esté donde esté: "pues nunca mejora su estado quien muda solamente de lugar y no de vida y costumbres" (129).

El pícaro siempre tendrá una connotación negativa. Por esta razón, tal y como lo hace Del Monte, apoyado en el Diccionario de autoridades, se le califica como "bajo, ruin, doloso, falto de honra y de vergüenza"; aunque luego matiza al decir que en los textos del género el significado aparece de forma más moderada, y será "alguien que está dedicado a humildes menesteres y no tiene oficio propio, sino que vive de manera provisional, recorriendo a amaños, vagabundo, sonsacador y pedigüeño" (Itinerario 11). Allí está la clave acerca de la pureza del pícaro, y en ellas se expresan los dos puntos de vista con los cuales la crítica define y clasifica al representante 
del género. Micó, al analizar la obra de Alemán, advierte la diferencia sustantiva entre los personajes Lázaro de Tormes y el protagonista de la novela del autor sevillano: 'Lázaro es un 'pobreto' que malvive entre Salamanca y Toledo, con el Guzmán de Alfarache, la picaresca se hace internacional y delictiva. A un hijo de desdicha le sucede "un hijo del ocio"' (32). En ocasiones, se validan estos dos significados para definir al personaje, con lo cual su presencia y figura se amplifica, como, a la vez, se diluye en lo que representa su real sustancia. Si se observa con detención, la primera de ellas coincide con la descripción del Guzmán y de Pablos; la otra, con la de Lázaro y, en parte, con la de Marcos de Obregón.

Ahora bien, Del Monte insiste en que el pícaro "está al margen de toda norma ética y regla social" (Itinerario 60). Bataillon agrega que el personaje "nace más bien en la ignominia que en la extrema miseria" (209). De acuerdo con esas definiciones, es preciso poner el acento en esas diferencias para concluir quién es, en concreto, la viva imagen de un pícaro. Lázaro, por ejemplo, siente cristiana compasión y piedad por su amo escudero, ya que comparte con él la poca comida que logra mendigando. Dicho personaje episódico esconde su pobreza y miseria para aparentar una imagen social de la cual ya no es parte, asunto que lleva a la solidaria acción del Lazarillo. El mozuelo protagonista, además, culmina su suerte infausta una vez que logra trabajar como aguador, lo que le permite resolver sus problemas de miseria: no delinque, no es un tahúr, menos alguien que engañe ni robe con oscuros propósitos. Ha escalado socialmente y, por ende, acepta las reglas del mundo al que ha accedido. El pícaro, en tanto, es consciente de la ruindad de sus actos, y no puede evitar recaer en ellos, pues, goza con esa vida picaresca: "Que los pícaros lo sean, jandar! Son pícaros y no me maravillo, pues cualquier bajeza les entalla, y se hizo a su medida, como a escoria de los hombres" (Alemán 227).

Por tales razones, la madera ética de ambos personajes tiene diferencias profundas. El pícaro Guzmán también fue mozo de muchos amos, asunto que Alemán importa del Lazarillo, que representa un referente ineludible, pero su protagonista irá por un camino distinto, en términos semánticos: "Mateo Alemán escribió 
su Guzmán de Alfarache, siguiendo la estela del Lazarillo. Y lo hace además manifiesto con la presencia de motivos y de palabras del relato de Lázaro en el texto. El género va a caracterizarse por la continua red de referencias entre las obras que lo componen" (Navarro Durán, Gużán LV).

En síntesis, todos los relatos que emergen de personajes de estratos sociales bajos hasta llegar a lo que se conoce como "apoteosis del pícaro" con el Gurmán de Alfarache, expresan matices que evidencian la evolución de este tipo de narraciones. El realismo que surge de los episodios que conciernen a algunos de los personajes marginales de la Celestina marca un punto de partida que continúa con la sátira erasmista del Lazarillo, una especie de germen del pícaro; para llegar, luego, al texto de Alemán, que representa una ácida crítica social a partir de un personaje bellaco que paga sus tropelías en las galeras, lugar desde donde decide relatar su confesional historia. De allí surge el nervio del género, y es donde encontrará su mayor expresividad. Además, tendrá una enorme resonancia en los relatos que le sucedieron. De esta forma, aquella narrativa transita y evoluciona con los textos cervantinos, la novela de Quevedo y Gregorio González, la novedosa picaresca femenina de López de Úbeda -o Baltasar de Navarrete- y la de Salas Barbadillo, hasta llegar al Marcos de Obregón de Vicente Espinel.

\section{Marcos de Obregón y la figura del pícaro}

El escudero se aleja del canon que define al arquetipo del pícaro. Aquella distancia tiene su raíz en las acciones bondadosas -predominantes en la novela- que Marcos realiza en cada capítulo, siempre aparejadas de un mensaje de justa moralidad que incluso permitía la autocrítica, si es que alguna mala conducta suya lo ameritase. Espinel no necesita justificar a su personaje, como Alemán con el Guzmanillo, quien se arrepiente de sus delitos cuando cuenta sus aventuras, moralizándolas por su contrario. Marcos, en cambio, se autoerige como modelo de rectitud. Aquel propósito se establece desde el prólogo de la obra, cuando el autor declara tanto las inten- 
ciones y el estilo que marcará su prosa, como el carácter que tendrá su personaje protagonista de los hechos que narra.

\subsection{El escudero y la crítica}

Obregón, como un celador de las conductas propias y ajenas, siempre acompaña las acciones de su relato con honrosas reflexiones. Así, se entiende que se indique que sea, en la práctica, un antipícaro (Bataillon 209). Sus palabras y acciones, que son los canales por donde se trasunta la voz del autor, tienen una acentuada impronta clerical. Con ello, la historia adquiere una tonalidad con evidentes tintes de expiación. El escudero, no en vano, advierte en el inicio del discurso de tipo confesional acerca de los errores cometidos en la tormentosa juventud, a causa de su comportamiento regido por la cólera. Estos recuerdos de antaño laceran su presente. La ansiada y recomendable "paciencia", que debe prevalecer en el ser humano para obrar con virtud, se erige como el antídoto perfecto. Con ella predica y cierra el texto, pues es la gran enseñanza que la vida le deja, de acuerdo al esquema axiológico que Espinel propone con estas antitéticas relaciones entre el bien y el mal. Dichos yerros, no obstante, parecen nimios al lado de los excesos de un pícaro Guzmanillo o un Pablos (Stamm 663). Por su parte, Pfandl indica que el personaje "es más manso e inocente que sus camaradas, sus aventuras no son ni remotamente tan patibularias como las de Guzmán y del Buscón, ni tampoco tan crudamente realistas como las de la Justina" (675). Parker lisa y llanamente dice que Marcos "no es un pícaro ni un delincuente, sino un observador de la vida hampona o de aventuras nada rudas ni crueles" (680). En efecto, la crítica ensalza el estatus moral del escudero, hecho que marcará, en términos generales, su distancia respecto de los cánones tradicionales del representante del género.

\subsection{La figura del picaro en el personaje Marcos de Obregón}

Sin embargo, al hurgar bien en los detalles del comportamiento del protagonista, es posible advertir que, en ciertas ocasiones, Marcos hace uso de las estratagemas y armas de los pícaros con el objeto 
de escarmentar o burlar a estos porque así lo merecen, para huir de situaciones escabrosas o también para ir en su propia defensa (Chandler 673). El escudero recurre a estas ingeniosas tretas y argucias cuando, por ejemplo, debe huir de los engaños de un matrimonio de truhanes en Sevilla, en el comienzo de la segunda relación. ${ }^{6}$ Lo hace, en una nueva oportunidad, cuando una mozuela quiso aprovecharse de sus dineros en Italia. La paradoja se advierte porque Marcos representa simbólicamente lo contrario de lo que el arquetipo significa. Hay ciertos elementos que emparentan a Marcos con el modélico paradigma: el vagabundaje y la pérdida de tiempo o el carácter travieso y burlón, aunque se asume que estos tenues rasgos lo alejan de la ruindad de los auténticos pícaros (Navarro González 146). Todo el grueso de la historia, y sus acciones ejemplares sobrecargadas con largos y excesivos excursos que restan ritmo al relato, logran cubrir con un disimulado velo algunas de las tropelías del escudero.

Sin duda, el pasaje donde la estela del pícaro está más acentuada en Marcos de Obregón corresponde a la aventura que vive en Italia, en la tercera relación, cuando acuchilla en el rostro a uno de los burladores con los cuales mantiene una pendencia. Por ese hecho violento y colérico, contrario a su prédica constante, es encarcelado. Posteriormente, logra escapar del encierro al engañar al carcelero, haciéndole creer que es alquimista y que ha fabricado un polvo que se convertirá en oro. El corolario a todos estos despropósitos y desequilibrios se produce cuando libera - tal y como el Quijote lo hiciera con su perturbada visión de la realidad- a unos galeotes que le ayudan en su intento de huir, asunto que culmina con éxito. Extrañamente, este acto queda impune. Es posible advertir que el comportamiento del escudero cruza sus propios límites y llega a ser incluso despiadado, por lo que le asigna claros rasgos picares-

\footnotetext{
${ }^{6}$ Estos lances y pendencias de juventud se vinculan y atribuyen a la propia vida del autor en tierras andaluzas. La famosa Sátira contra las damas de Sevilla, que incluso aparece mencionada en el Quijote, es considerada un texto que retrata aquella época.
} 
cos derivados del modelo del autor rondeño, el Guzmán de Alfarache (Navarro González 145) o del mismo Pablos del Buscón. Espinel acerca a su personaje a esa imagen pícara, aunque le aleja de aquella rápidamente, consciente de que aquellos movimientos no inhiben la sustancia de su mensaje final, ni entorpecen el ethos antipicaresco con el cual construye a su personaje. Esta dicotomía -y evidente contradicción en la construcción de la arquitectura moral del personaje, basada en una rígida caracterización bajo el parámetro de la prudencia, pero con algunos matices oscuros que no alcanzan a ensombrecer esta figura-, se debe a dos factores provenientes del propósito de la fábula:

Para explicar las circunstancias en que Marcos representa el papel de pícaro hay que atender a la finalidad del adoctrinamiento (docere) que Espinel asume para su novela, a la moralidad mantenida a lo largo de todo el discurso narrativo... A pesar, por encima de la condición de pícaro que Espinel le ha obligado a realizar para cumplir con el delectare, Marcos se nos ofrece como modelo de virtud y honra (Lara Garrido y Rallo Gruss 654-55).

Por contrapartida, hay tres episodios en donde se señala a los pícaros como personajes contrapuestos y equidistantes a la altura moral de Obregón. Incluso, el escudero es capaz de contrastar opiniones y puntos de vista con ellos acerca de aquella condición humana. El primer caso se encuentra apenas comenzado el texto, cuando unos pícaros observan a Fernando el tío, héroe de Flandes que desembarcaba en Barcelona, a quien llaman, también, el "pícaro" por sus travesuras de juventud. La reflexión, que a continuación realiza el escudero sobre el suceso, revela el negativo sema que pesa sobre la noción del apelativo, asunto que Espinel quiere resaltar a viva voz. Aunque el histórico personaje asume el apodo con un toque de buen humor, Marcos subraya que se trata de un verdadero agravio: "Así que, aun de aquellas injurias que derechamente vienen a ofendernos, habemos de procurar por los mismos filos hacer triaca del veneno, gusto del disgusto, donaire de la pesadumbre y risa de la ofensa" (Espinel 22). 
La siguiente situación acontece cuando un pícaro anónimo asoma en el episodio del tinelo, en el descanso octavo de la primera relación. Todo el ambiente de este cuadro narrativo alude a obras a las cuales Espinel recurre para situar al personaje, como la Tinelaria de Torres Naharro, el Buscón o la segunda parte espuria del Quijote y el Lazarillo, pues hay un personaje -el escudero pobre- que remite a este último texto (Navarro Durán, Marcos XVII). En esta ocasión, el pícaro alega no recibir buen trato en cuanto a las raciones de comida. Un gentilhombre carga en feroz diatriba contra esta queja, lo que da luces sobre el punto de vista "oficial" que se quiere perfilar acerca del arquetipo: "-¡Oh villano -dijo el otro-, deshonra buenos! ¿Y tal has de decir? Los mal nacidos como este infaman las casas de los señores, que no saben tener paciencia ni sufrir mal día; luego echan faltas en la calle; no se contentan con el respeto que los tienen por servir a quien sirven" (Espinel 71).

Poco a poco, se va moldeando con mayor nitidez la idea del pícaro que el autor va delineando en estos breves diálogos bajo parámetros que denotan rechazo. Marcos interviene en la discusión, reforzando la opinión del gentilhombre, pues solicita respeto y discreción al mozuelo por la gente de oficio superior. Sus palabras ponen el acento sobre la condición de (mal)hablador de un truhán de tales características:

-Déjelo Vuesa Merced -dijo otro gentilhombre-, que, si el pícaro habla, por todos habla; que si jugando sentencian una suerte que no sea en su favor, luego dice que lo hacen porque le den barato. Fuera de ser el que nos a todos en mal con el señor; congraciador general y celebrador y reidor de lo que el señor dice, arcaduz de la oreja, manantial de chismes, estafeta de lo que no pasa en todo el mundo. Si dice algo, él lo celebra y quiere que se lo celebren todos; si otro dice o hace algo bueno, lo procura derribar y deshacer; si malo, a pura risa lo persigue; y si alguno le parece que se le va entrando al señor en la voluntad, por mil caminos le descompone. Estas y otras muchas cosas le dije yo de mi persona a la suya con cinco palmos de espalda (Espinel 72). 
En tanto, en el descanso quince de la tercera relación, un pícaro irrumpe en escena. El escudero y los oyentes se maravillan con la amena retórica del personaje episódico, quien se había metido a fraile para poder solventar su vida. En el monasterio, usaba su habilidad y argucias para saciar su hambre infinita. ${ }^{7}$ De esta forma, robaba y guardaba panecillos que clavaba bajo su cama. Todo ello, sin duda, remite a las trazas que usaba Lázaro con el cura que le negaba el alimento en el Lazarillo. Así, echando mano a su picaresca escala de valores, el frailecillo justifica su acto de defensa, que consistió en romper unas colmenas para que las abejas atacaran a sus perseguidores, enviados por el agraviado superior que descubre sus tropelías. Espinel cede el punto de vista a su personaje, quien apoya su razonamiento con una analogía singular. Se trata de una breve fábula que remite a las historias del clásico griego Esopo, otro recurso intertextual al cual el autor andaluz recurre con frecuencia en su novela:

-Sea como fuere; que siempre oí decir que tiene un hombre obligación de guardarse a sí propio. Que un cordero mató a un lobo, por huir de él, en una trampa que había puesto el pastor muy encubierta de yerba, con una culebra muerta puesta encima. Vio el lobo que venía muy determinado a cogerlo, y corriendo el cordero hacia donde estaba su pastor, la cuando llegó a la trampa, vio la culebra y espantose de ella, dio un salto; pero el lobo que iba en su alcance, dio en la trampa y quebrose las piernas. $\mathrm{Y}$ si un cordero quiere defenderse con daño ajeno, ¿por qué no lo hará un hombre? (Espinel 310).

\footnotetext{
${ }^{7}$ Este tópico es otro aspecto relevante y característico de los relatos picarescos: "el torso de la interpretación vigente de ella consiste en ver que su tema fundamental es el hambre" (Marías 8). De todas formas, ello no quiere decir que la condición del protagonista tiene que ser necesariamente la de un menesteroso o pordiosero, como representante de su condición social miserable. Muchas veces, esa circunstancia, la penuria alimenticia, está marcada por las aventuras y desventuras causadas por sus propios yerros y malandanzas del personaje, tal y como sucede al Guzmán o a Pablos.
} 
La participación aunque marginal de estos auténticos pícaros en estos tres episodios independientes entre sí, pero insertos deliberadamente por el autor para develar su ideología sobre este tema central, no tiene mayor relevancia en la historia principal, de acuerdo con los acontecimientos vitales y las aventuras relatadas por Obregón. Son útiles, eso sí, no solo para dotar de cierta gracia al relato a través de ellos, sino también para reforzar el sentido axiológico de la novela, uno de los propósitos finales del autor de Ronda. En relación con la imagen de su personaje, el mensaje que Espinel envía es rotundo: los pícaros son otros, y son ellos quienes hablan desde sus particulares visiones y ética, rechazadas por la voz del protagonista (y, por cierto, de la suya); aunque, de todos modos, queda en evidencia que Marcos de Obregón puede, en ocasiones, valerse de sus malas artes para amoldarlos a sus propios fines estéticos. El autor de Ronda construye con estos episodios un discurso antipicaresco explícito, lo que no implica dotar al escudero de algunos de sus rasgos. La palabra y su praxis no siempre congenian de manera plena.

Stamm, en un plano comparativo, dirige su mirada hacia el autor para describir la conducta del personaje, propia de una moral aburguesada (667). Resulta, por tanto, poco probable que Marcos pudiera ser un pícaro a carta cabal, aunque a veces asomen en su actuar ciertas actitudes que pertenezcan al canon, porque el protagonista remite directamente a la figura del escritor. El origen hidalgo de Marcos, compartido con el de su creador, es como su "herencia espiritual” (Del Monte, Marcos 677). El escudero no tiene un origen vil, no es ladrón, ni fullero. ¿Podría tener carácter de ruin, ladrón, truhán y estafador -es decir, el de un auténtico pícaro- un personaje que es músico, políglota, que escribe odas famosas, que pasó por Salamanca ${ }^{8}$ para dotarse de erudición, que se gana la vida siendo

\footnotetext{
${ }^{8}$ Navarro Durán destaca que la mejor prueba de lo literario del género es la condición de universitarios que tienen los pícaros representativos como Guzmán o Pablos, pues de esta forma el autor valida y respalda la cultura del protagonista, quien así puede dar verosimilitud a su relato, así como justificar la escritura de su autobiografía (Pícaros 295-96). Para Espinel, en tanto, esto resultó ser más fácil,
} 
consejero moral de un matrimonio burgués o de diversos caballeros, que es ayo de unos hijos de una importante autoridad de Argel, ganándose la confianza de todos ellos por sus rectas acciones, y que, por si fuera poco, cura a las personas como ensalmador? A todas luces, aquello resulta poco factible, porque, de ser así, comprometía la imagen del propio Espinel. Marcos compartía demasiados rasgos comunes con el escritor, factor que implicaba fijar un límite de partida a una presunción de tal naturaleza. El autor andaluz, mediante esa técnica de superposición con la cual se funde con su personaje, cuida de no exceder los márgenes que entreguen una positiva semblanza de Marcos de Obregón. Es un asunto de imagen, que debía ser contenida, dado el carácter de la obra y su protagonista, que trasciende hacia lo extratextual. Queda en evidencia que este relato, tipo autoficción, debía, entonces, guardar las apariencias con quien cedía los principales acontecimientos vitales para enriquecerlo, pues el autor era, además, representante de la Iglesia.

No cabe duda que las andanzas de Guzmán, Pablos, Guitón, Rinconete y Cortadillo fueron claves para la confección de algunas de las acciones pícaras que se hallan en el texto. Estos personajes no fueron cercanos en lo biográfico con la figura de sus autores como sí la tuvo Espinel. La ausencia de ese nexo tan directo permitió la libertad de la pluma de esos autores para que sus protagonistas cruzaran líneas rojas y terrenos pantanosos. El escudero no goza de ese privilegio a plenitud. Las aventuras de Marcos de Obregón con acento picaresco son coincidentes con las de sus referentes, y están insertas para otorgarle ritmo y ciertas notas de gracia a una narración en exceso moralizadora. Por tanto, estos pasajes -los más divertidos y con mayor dinamismo en las acciones- tienen orígenes plenamente literarios, aunque no se excluyen posibles episodios vitales verídicos a los cuales el autor pudo recurrir para purgar, en su relato autobiográfico y con carácter de autoconfesión, sus yerros adolescentes.

pues aprovecha este mismo procedimiento para literaturizar su propio paso por Salamanca. De esta forma, traspasa el caudal educativo de esos años de aula a su escudero para que este escribiera su biografía novelada. 
De esa manera, el autor cumplía con el docere y delectare de su fábula. Los episodios en donde se vincula directamente la figura del autor con el personaje protagonista -curiosamente- tienen un tono más serio y solemne. Así ocurre, por ejemplo, cuando Marcos alude a la participación de Vicente Espinel en las exequias de Ana de Austria a través de la composición de los escritos en verso de la ceremonia, pero también cuando el escudero regresa a Ronda, sitio del cual se queja con amargura por la envidia de la cual fuera víctima; o, de igual forma, cuando el escudero exalta los versos de Espinel que provocaron una emocionada reacción de una dama cortesana.

\section{Influencia estructural de la novela picaresca en Marcos de Obregón}

La novela tiene como principal referente al género de la picaresca, particularmente el Guzmán de Alfarache. Los elementos estructurales, el cuadro realista, como también la inclusión de ciertos personajes y sus acciones, conducen a una relación más que casual con ese y otros textos paradigmáticos de esa corriente literaria.

Existen tres modos con las cuales la crítica intenta relacionar la novela de Espinel con el género. El primero está basado solamente en las características de esta corriente, el segundo fija la mirada de forma exclusiva en el personaje y, finalmente, una modalidad ecléctica, que incluye el análisis de los dos estamentos mencionados (Lara Garrido y Rallo Gruss 637-39). Esta última pareciera ser la metodología más adecuada para entender la dimensión de un texto que absorbe aspectos no solo de un determinado género, sino de

muchos otros como la novela bizantina y la miscelánea, aunque sea el primero el que predomine en sus páginas.

\subsection{Marcos de Obregón y la valoración de la crítica}

La novela del rondeño fija la posición de Espinel, según Carrasco Urgoiti, como una efectiva "reacción frente al principal supuesto del género picaresco, cuya enseñanza deriva de la conducta errada del protagonista" (630) además, agrega: "ni por la coyuntura his- 
tórica, ni por la materia y estructura misma de la obra puede desgajarse totalmente Marcos de Obregón del conjunto novelístico que promueve la obra de Alemán, y de hecho hará un papel crucial en la propagación del género a otras literaturas" (630).

El cambio fundamental radica en la técnica narrativa autobiográfica, ya que el personaje realiza algunas modificaciones en el procedimiento, como contar desde su avanzada edad episodios de su madurez antes de adentrarse en sus propios orígenes. Esto implica que el personaje estará plenamente integrado a su condición social, por lo que no es necesario explicar una conducta posterior. Lo mismo opina Rey, ya que a su juicio la verdadera renovación del género picaresco que Espinel realiza "estriba en el nuevo tratamiento del narrador... El yo narrativo corresponde más a un testigo sabio y fidedigno que a un pícaro volcado sobre su yo" (681). Rallo Gruss expresa que Espinel distorsionó el género no solo por el personaje honrado y bueno, sino también por el valor del viaje y la técnica narrativa in medias res (684). En efecto, la utilización de la técnica ${ }^{9}$ por parte del escritor rondeño en su texto aporta una interesante innovación. Se trata de una doble retrospectiva que permite observar el enfoque narrativo desde varios planos.

Rico señala que la novela de Espinel "ni por personaje ni por estructura es una novela picaresca, aunque aprenda bastante del género" (128). Stamm examina la postura de Rico y cuestiona la no

\footnotetext{
${ }^{9}$ El modelo narrativo del Guzmán, como el del Lazarillo, es muy similar al del Marcos de Obregón, pero, no se olvide, la perspectiva vital del protagonista de estos relatos no es la misma que la utilizada por el escudero, pues su edad no era tan avanzada. Además, el texto de Alemán anunciaba una continuación de la historia que nunca vio la luz. Espinel concluye su obra como si fuera un testamento, sin posibilidad alguna de proseguir una secuela. Es, por tanto, una historia cerrada. Por otro lado, la técnica narrativa in medias res había sido utilizada por otros referentes y modelos que iban mucho más allá del género de la picaresca, como la propia novela paradigmática del género bizantino, tan alabada por preceptistas y autores: Las etiópicas de Heliodoro, el Persiles y el Coloquio de los perros de Cervantes, así como el Peregrino en su patria de Lope de Vega, lecturas presentes en el cuerpo de la historia de Espinel.
} 
delimitación de ese "bastante", pues el estudioso no lo explicita (660). Zamora es quizás el crítico que menos relación observa entre el texto de Espinel y el género, y la califica como una novela extraña con una médula que no es la picaresca (863). Talens, por su parte, plantea en tono tajante que la novela es antipicaresca donde las haya (18). Para Del Monte, lo único de picaresco que tiene la novela es "el tema de los cambios de amo del protagonista, y el de la genealogía". Pero incluso, dentro de estos límites, el pícaro es como un enemigo de sus amos, todo lo contrario del escudero de Espinel: "Marcos es el amigo fiel y el prudente consejero de ellos; y mientras los antecesores del pícaro, con sus vicios y su miseria, casi son el símbolo de su abyecto destino" (Marcos 676). Parker dice que Obregón "tiene más de una novela de aventuras que de picaresca" (680). Gili Gaya opina que esta narración es sin duda la menos picaresca, aunque la admite como dentro del género, pero agrega además que lo picaresco es solamente episódico (19-21). Para Rallo Gruss la forma autobiográfica, obligada por la elección del molde picaresco, da voz tanto al personaje como a Espinel. Por ello, el autor, "no quería que le confundieran con aquel escudero, pero necesitaba proyectarse porque el contenido doctrinal es diametralmente diverso del que se ficcionaba en la obra de Alemán” (683). Lara Garrido y Rallo Gruss, señalan que Marcos de Obregón representa, en definitiva, la culminación del espacio picaresco (657).

Estas diferentes visiones no apuntan, sin embargo, al asunto central que implica la real distancia que Espinel realiza respecto de los relatos precedentes. Espinel considera elementos que adquiere de estas historias para su proyecto literario narrativo. Prueba de ello representa la inclusión de la historia bizantina de la tercera relación, con dos personajes episódicos que adquieren el protagonismo del relato. A pesar de ello, siguen siendo los acontecimientos biográficos del escudero, cercanos o coincidentes con los del autor, la clave para entender esta relación ambigua y tirante con el género.

\subsection{La estructura de la obray sus modelos}

La división de la obra en tres grandes bloques o relaciones sigue, por cierto, el paradigma del Guðmán, el Guðmán apócrifo y el del 
Buscón. Dos elementos en la estructura narrativa indican la influencia de la picaresca: la técnica literaria y la división por capítulos.

Marcos de Obregón está construido con los mismos procedimientos que Alemán utilizó para organizar el relato del pícaro. Los elementos estructurales básicos que Espinel adopta del texto del novelista sevillano son tres: la autobiografía del personaje central, las historias y cuentos más o menos directamente relacionados con el narrador, $\mathrm{y}$, por último, los comentarios y disquisiciones didáctico-morales y satíricas (Navarro González 89).

En conclusión, la novela Marcos de Obregón tiene muchas conexiones con el género picaresco, cuyo texto canónico lo representa el Guzmán de Alfarache. Espinel usó y transformó ciertos elementos extraídos de las historias autobiográficas de personajes de baja estofa, que leyó ávidamente, para amoldarlos a su propuesta de fábula y novelar su propia vida. Esta obra, por tanto, representa un paso más allá en el desarrollo del género autobiográfico, pues se convierte en unos de los primeros relatos en forma de autoficción, asunto que constituye todo un primitivo y novedoso rasgo de modernidad en pleno periodo Barroco.

Espinel recoge elementos estructurales de la picaresca, como por ejemplo la división del libro en tres grandes partes que llama Relaciones, así como el relato en primera persona de un personaje itinerante, mozo de muchos amos, que repasa sus episodios vitales; esta vez, eso sí, desde su reposada vejez en un hospital de ancianos.

La novela tendrá como propósitos explícitos adoctrinar y deleitar a sus posibles lectores. Para cumplir con el primero de ellos, el autor aprovechará su propia impronta clerical, que no es otra que la de un fiel representante del catolicismo español postridentino. Este hecho es trascendental en la historia, puesto que la imagen del autor, fundida en su personaje a través de la técnica de la superposición, hará que el protagonista se aleje definitivamente de la imagen prototípica del pícaro, figura que es continuamente denostada en las páginas del texto. Pese a ello, el escudero protagonista tendrá, en ciertas ocasiones, las actitudes propias de un pícaro, aunque ellas no ensombrecen la moralidad del personaje, pues están desplegadas en el texto de forma que no afectan el discurso antipicaresco 
-predominante en la historia-, dirigido a los personajes episódicos que tienen dicha condición. Con estas acciones, pletóricos de divertidos acontecimientos, el autor cumple entonces con el segundo de sus propósitos.

El autor, en suma, nunca quiso escribir el relato de un pícaro, sino solo aprovechar el esquema que el género le ofrecía para contar su propia historia novelada, asunto que impide asignarle rasgos propios de un representante puro de la picaresca a un personaje tan parecido a él, pues ello representaba un peligro para su imagen. No hay, entonces, una crisis ni término del género en esta obra en prosa. El escritor rondeño, qué duda cabe, solo intentó ensalzar, a través del personaje Marcos de Obregón, su propia figura de artística de latinista, músico y poeta reconocido por sus pares en aquel tiempo, al que ahora le sumaría el de prosista con su novela que escribe para la posteridad, en el ocaso de su vida. Para tal propósito recurre a los moldes literarios que tenía al alcance de su mano, entre ellos, por supuesto, estaba el de la picaresca.

\section{Obras consultadas}

Alemán, Mateo. Guгmán de Alfarache. Ed. José María Micó. Madrid: Cátedra, 1997.

- Guzmán de Alfarache. Ed. Rosa Navarro Durán. Madrid: Biblioteca Castro, 2004.

Bajtín, Mijail. Teoría y estética de la novela. Madrid: Taurus, 1989.

Bataillon, Marcel. Picaros y picaresca. Barcelona: Taurus, 1969.

Carrasco Urgoiti, María Soledad. "Marcos de Obregón: Modelos, estructura y géneros II”. Lara Garrido y Garrote Bernal 619-637.

Chandler, Frank. W. "Marcos de Obregón en la picaresca I". Lara Garrido y Garrote Bernal 669-674.

Covarruvias, Sebastián de. Tesoro de la lengua castellana o española. Ed. de Martín de Riquer. Barcelona: Alta Fulla, 1998.

Del Monte, Alberto. “Marcos de Obregón en la picaresca III”. Lara Garrido y Garrote Bernal 676-677.

—. Itinerario de la novela picaresca. Barcelona: Lumen, 1971. 
Espinel, Vicente. Relaciones de la vida del escudero Marcos de Obregón. Ed. Rosa Navarro Durán. Madrid: Biblioteca Castro, 2008.

— Vida del escudero Marcos de Obregón. Ed. Samuel Gili Gaya. Madrid: Espasa Calpe, 1951.

Genette, Gérard. Palimpsestos. La literatura en segundo grado. Madrid: Taurus, 1989.

Heiple, Daniel L. 'El apellido 'pícaro' se deriva de 'Picar'. Nueva documentación sobre su etimología”. La Picaresca. Orígenes, textos y estructuras. Madrid: Fundación Universitaria Española, 1979. 217-230.

Lara Garrido, José y Asunción Rallo Gruss. "Poética narrativa y discurso picaresco en La vida del escudero Marcos de Obregón". Lara Garrido y Garrote Bernal 637-657.

Lara Garrido, José y Gaspar Garrote Bernal, comps. Vicente Espinel. Historia y antología de la crítica. 2 vols. Málaga: Servicio de Publicaciones Diputación de Provincia de Málaga, 1993.

Lázaro Carreter, Fernando. Lazarillo de Tormes en la picaresca. Madrid: Ariel, 1972.

Marías, Julián. "Prólogo". La picaresca española. Barcelona: Nauta, 1969. 7-14.

Navarro Durán, Rosa. Pícaros, ninfas y rufianes. Madrid: Edaf, 2012.

Navarro González, Alberto. Vicente Espinel. Músico, poeta y novelista andalur. Salamanca: Universidad de Salamanca, 1977.

Parker, Alexander A. "Marcos de Obregón en la picaresca V". Lara Garrido y Garrote Bernal 679- 680.

Pfandl, Ludwig. "Marcos de Obregón en la picaresca II". Lara Garrido y Garrote Bernal 674-675.

Quevedo, Francisco De. La vida del buscón. Ed. Rosa Navarro Durán. Madrid: Biblioteca Castro, 2004.

Rallo Gruss, Asunción. “Marcos de Obregón en la picaresca VII”. Lara Garrido y Garrote Bernal 682-684.

Rey, Alfonso. "Marcos de Obregón en la picaresca VI". Lara Garrido y Garrote Bernal. 680-682.

Rico, Francisco. La novela picaresca y el punto de vista. $5^{\circ}$ ed. Barcelona: Seix Barral, 2000. 
Rodríguez, Milagros. "La Picaresca: perfiles de un complejo proceso literario". Le roman PICARESQUE. París: Ellipses, 2006. 47- 57. Stamm, James R. "Marcos de Obregón: La picaresca aburguesada". Lara Garrido y Garrote Bernal 659-668.

Talens, Jenaro. Novela picaresca y práctica de la trasgresión. Madrid: Júcar, 1975.

Teijeiro, Miguel Ángel. La novela bizantina española. Apuntes para una revisión del género. Extremadura: Universidad de Extremadura, 1988.

Zamora Vicente, Alonso. “Honor, religión y jerarquía social”. Lara Garrido y Garrote Bernal. 863- 890. 